\title{
Tradução de
}

\section{Uma revolta contra os corpos intermediários}

Nadia Urbinati. "A Revolt against Intermediary Bodies", Constellations, 22:4 (2015), 477-

$486^{*}$

Sue lamamoto**

Gabriela Rosa***

O que cientistas políticos descrevem como democracias consolidadas ou ocidentais está em um processo de mudança significativa e, como em alguns países europeus, enfrenta desafios cujas consequências para suas instituições e procedimentos ainda são difíceis de avaliar. A profundidade e a vastidão da crise econômica atual são fatores importantes que nos ajudam a explicar tais mutações na democracia representativa, apesar de não serem os únicos. Essa crise econômica ocorre em um momento no qual a vida privada e a esfera pública experimentam o impacto da internet nas estratégias de comunicação e na provisão de informação talvez a revolução tecnológica mais importante no campo da política depois da invenção de imprensa mecânica em 1450. Pela primeira vez depois da Segunda Guerra Mundial, democracias constitucionais estão sob tensão, tanto porque sua capacidade de lidar com a crise econômica e social é agora questionada, quanto porque seus métodos rotineiros de participação política e de tomada de decisão foram estilhaçados pela nova tecnologia midiática. Essas mudanças pertencem tanto ao conteúdo da

\footnotetext{
* Nadia Urbinati é professora de teoria política (Kyriakos Tsakopoulos) no Departamento de Ciência Política da Universidade de Columbia. Seu livro mais recente é Democracy Disfigured: Opinion, Truth and the People (Harvard University Press, 2014). A revista Leviathan agradece a autora a gentileza de autorizar esta tradução.

** Professora do Departamento de Ciência Política da UFBA, doutora em Ciência Política pela Queen Mary University of London. E-mail: sueiamamoto@yahoo.com.

** Mestre e doutoranda em Ciência Política no Programa de Pós-Graduação em Ciência Política da USP e pesquisadora do Gepô (Grupo de Estudos de Gênero e Política do DCP-USP). E-mail: gabrielargrosa@gmail.com.
} 
política quanto aos métodos e estilo de expressão política. Como consequência, os cortes governamentais em políticas sociais e o aumento rápido do desemprego reacenderam o nacionalismo em sentidos e maneiras cuja escalada em intensidade é impressionante, mas que não são diretamente identificáveis com o velho fenômeno antidemocrático que atormentou a Europa depois da Grande Depressão.

Ideologias tradicionais de direita circularam e estão circulando junto com a difusão da participação política: conteúdos antidemocráticos aparecem de mãos dadas com cidadãos democraticamente expressando suas opiniões de maneira nunca antes tão direta. Para dar alguns exemplos deste fenômeno esquizofrênico no qual a velha história volta e coexiste com uma história completamente nova: estamos testemunhando, por um lado, a reemergência de líderes carismáticos e demagogos que exploram a revolta popular contra a impotência do governo e a jogam contra a democracia liberal e parlamentar; e, por outro lado, um processo que vai em direção quase oposta, na medida em que reivindica promover a difusão da política tendo em vista a reafirmação da voz de cidadãos comuns contra as elites políticas estabelecidas. Neste artigo, eu esboço casos destes dois tipos de histórias, mas focarei nas que são novas, que proponho abordar como casos de revolta contra corpos intermediários partidos políticos e jornalismo profissional - que tornaram possível a estabilização do governo representativo nos dois últimos séculos. Vou interpretar estas histórias completamente novas como como parte da transformação da representação política cujas consequências ainda são indeterminadas.

\section{Uma revolta contra os corpos intermediários}

No Espírito das Leis, Montesquieu caracterizou os corpos intermediários como condições essenciais para o governo moderado porque eles são poderes compensatórios contra a tendência endógena de qualquer poder soberano ser monopolizado pelos seus portadores, sejam eles um, os poucos, ou os muitos. 0 soberano necessita ser limitado tanto pela divisão das funções estatais e pelo sistema de vetos, quanto pelas entidades ou práticas autônomas que a sociedade mesma produz. O pluralismo, portanto, não é meramente uma questão de engenharia 
institucional, mas também precisa estar enraizado na sociedade. Nessa obra, Montesquieu concluiu que as repúblicas italianas humanistas fatalmente tendiam ao despotismo (Signoria) porque suas sociedades não eram verdadeiramente pluralistas. ${ }^{1}$ Meu objetivo não é analisar as implicações anti-igualitárias do republicanismo constitucional na tradição de Montesquieu. Em vez disso, minha intenção é aplicar às democracias contemporâneas a teoria de Montesquieu segundo a qual corpos intermediários são essenciais tanto para articular o poder quanto para obstruir a sua tendência de concentração. Acompanho, então, Alexis de Tocqueville, que estendeu a estratégia de moderação política de Montesquieu à democracia representativa e listou dois corpos intermediários cruciais - a imprensa e os partidos políticos - adequados a um governo articulado em torno da igualdade política e do sufrágio universal.

Com relação à imprensa, Tocqueville reafirmou na Democracia na América três funções principais originadas no seu pluralismo: dispersão, ou a tendência da liberdade de expressão em descentralizar o poder e gerar pluralismo de materiais impressos que iriam se contrapor ao espírito centralizador da soberania popular; vigilância, ou a capacidade da imprensa de questionar o poder que a opinião da maioria tem de entranhar-se na vida das pessoas e assim fortalecer a autoridade política; e autoempoderamento, ou a tendência do pluralismo de formação de opinião em estabilizar as perspectivas das pessoas, não porque cidadãos têm certeza de que as opiniões que a imprensa divulga são verdadeiras, mas porque eles sentem que elas são seus próprios produtos.

Com relação às associações políticas, Tocqueville as definia em contraposição às associações civis. Associações civis vinculam (e dividem) indivíduos conforme suas preocupações e interesses específicos e frequentemente unidimensionais; elas produzem fragmentação "ad infinitum sobre questões de detalhes" que dificilmente teriam um escopo geral já que a vida das associações civis depende do fechamento relativo das suas fronteiras. Mas os partidos políticos são associações que vinculam (e dividem) indivíduos conforme suas interpretações avaliativas de problemas gerais, ou que têm "igual importância para todas as partes do país". Partidos políticos

\footnotetext{
${ }^{1}$ Charles-Louis de Secondat, Barão de Montesquieu, The Spirit of the Laws, traduzido por Anne M. Choler, Basia Carolyn Miller e Harold Samuel Stone (Cambridge: Cambridge University Press, 1989), 18088.
} 
interrompem a fragmentação, contudo, não por impor homogeneidade ou por encobrir diferenças (produzindo a sociedade inteira na imagem de um partido), mas por criar novas formas de diferença, como o partidarismo político, que levantam e interpretam demandas, atraem pessoas e conduzem campanhas eleitorais. ${ }^{2}$

Transformações recentes em algumas democracias europeias atestam a revolta contra a forma na qual esses dois corpos intermediários, que fizeram funcionar governos representativos, estiveram organizados nas décadas passadas. Ao mesmo tempo, o processo de simplificação horizontal da participação que essa revolta gerou estabelece o que eu chamo de democracia representativa de transmissão ao vivo, que se move pela lógica de tornar direta a democracia representativa, e consequentemente impulsionando algo que não é identificável com a democracia direta. Essa história completamente nova pode ser apresentada como uma tentativa de promover comunicação direta entre cidadãos e seus representantes eleitos, no intuito de alcançar controle visual da atividade dos líderes e intervenção direta na forma como parlamentos eleitos são conduzidos e no que dizem e pensam os políticos eleitos. A internet facilita essa prática de jornalismo autoproduzido (self-made) e de democracia eleitoral autogerida, enquanto encoraja cidadãos a experimentar com novos estilos de representação que podem desviar das clássicas práticas mediadas; e arrisca um tipo de mandato ou controle sobre indivíduos eleitos sem a necessidade de imposição legal, como o clássico mandato imperativo. Os objetos de contestação na democracia representativa via internet são, portanto, dois: os meios de comunicação tradicionais ou profissionais e o partido político, corpos intermediários que até este momento ocuparam o espaço entre as instituições estatais e a sociedade civil e,

\footnotetext{
${ }^{2}$ Alexis de Tocqueville, Democracy in America, traduzido por J. P. Mayer (New York: Harper Perennial, 1969), 174-75. Antecipando a diferenciação de Max Weber entre o partido ideológico e o partido da máquina eleitoral, Tocqueville distinguiu os "grandes partidos políticos" dos "pequenos partidos" e sugeriu que, enquanto os últimos agregavam interesses "sem fé política", os primeiros unificavam cidadãos por meio de princípios e interpretações sobre o destino geral do país. Tocqueville não argumentou que $o$ interesses privados operam somente nos partidos pequenos, mas percebeu que em grandes partidos políticos os interesses eram ocultos "sob o véu do interesse público". Similar à distinção de Tocqueville e como uma antecipação de Weber, havia também a distinção de Hegel entre hommes d'etat e homme à principes, que prefigurava duas formas diferentes de partido. Ver George Wilhelm Friedrich Hegel, "The English Reform Bill," in Hegel, Political Writings, traduzido por Thomas Malcolm Knox e Z. A. Pelczynski (Oxford: Clarendon Press, 1964), 325; Max Weber, "Parliament and Government in Germany under a New Political Order," em Max Weber, Political Writings, org. Peter Lassman and Ronald Speirs (Cambridge: Cambridge University Press, 1994), 152-54.
} 
ademais, moldaram opiniões políticas e exerceram controle sobre seus representantes eleitos.

Minha conclusão preliminar será a de que devemos evitar sermos afoitos na leitura destas mutações como um renascimento da democracia direta. Apesar de poderem ser entendidas como uma reafirmação do clássico ideal democrático de "poder ao povo", as ondas recentes de contestações anti-establishment são diferentes do que nós aprendemos das revoluções passadas (1848, 1871 e 1968). Essas revoluções anteriores reivindicavam autonomia política e em nome dela questionavam a reduzida distribuição de poder eleitoral (1848), a representação com mandato livre (1871), e a democracia eleitoral de maneira mais geral (1968). Mas essas ondas recentes de contestação da democracia representativa não reivindicam autonomia política no estilo democrático clássico ou como o poder direto versus o poder indireto dos cidadãos de tomarem decisões. ${ }^{3} \mathrm{Na}$ linguagem de Pierre Rosanvallon, nós podemos dizer que estas novas ondas de contestação da política constituída atestam um desejo de monitorar e controlar instituições e líderes; ou seja, de manter um tipo de poder negativo que demanda julgamento direto e inspeção ao invés de um poder positivo de tomada de decisão. Ele constitui uma fiscalização censória por cidadãos cuja aspiração é de participação ocular, portanto vigilância, ao invés de autogoverno. ${ }^{4}$

Uma democracia representativa de transmissão ao vivo demanda transparência. Cidadãos querem ver o que líderes fazem, e eles querem interagir com eles por meio da internet e sem os partidos políticos, como o público faz com os atores no palco. Ao invés de uma democracia composta por cidadãos autogovernados que querem decidir diretamente, a exemplo do mito de Atenas antiga, essa história completamente nova nos traz de volta algo dos plebeus romanos que interagiam com seus líderes no Forum não para substituí-los no governo, mas para sentir que podiam controlá-los ao imporIhes o peso da sua vigilância. Os plebeus tornaram custoso o desejo das elites por poder, e a privacidade era o custo que a elite teve que pagar. Isso é o que nós testemunhamos hoje. Apesar de algumas notáveis transformações, a política de uma democracia representativa de transmissão ao vivo não é mais democrática do que

\footnotetext{
${ }^{3}$ Eu desenvolvi a comparação entre estes novos fenômenos e revoluções prévias em Democrazia in diretta: Le nuove sfide alla rappresentanza (Milan: Feltrinelli, 2013).

${ }^{4}$ Pierre Rosanvallon, La Contre-démocraties: La politique à l'âge de la défiance (Parigi: Seuil, 2006).
} 
quando a imprensa profissional (accredited) e os partidos políticos possuíam um papel mais determinante; ela é, contudo, mais barulhenta e voyeurística, mais guiada pelas emoções e menos aglutinada em torno de algumas ideias e projetos centrais.

\section{A nova velha história e duas histórias completamente novas}

Em 11 de março de 2013, o parlamento húngaro, com Fidesz como seu partido majoritário, aprovou mudanças na constituição que diminuíam o poder da Corte Constitucional e direitos civis, o que promoveu uma democracia "majoritarianista" (majoritarianist) - uma nova versão da velha tirania da maioria eleita. Entre os vinte e dois artigos modificados, encontram-se alguns que tornam mais fácil para o governo limitar as liberdades de expressão e de associação política, alguns que criminalizam pessoas sem-teto que dormem em áreas públicas, alguns que proíbem estudantes que se formaram em universidades públicas a emigrarem antes de dez anos da sua formatura, e alguns que subvertem os princípios constitutivos da democracia liberal, como a separação dos poderes e o controle constitucional do processo legislativo; de fato, alguns artigos retiram da Corte Constitucional o poder de intervir no conteúdo de reformas constitucionais e de anular a validade de decisões prévias da corte. Ao abordar as (brandas) questões levantadas pela União Europeia, ${ }^{5}$ Viktor Orbán, líder do Fidesz e principal entusiasta da reforma, tratou do encontro parlamentar que aprovaria as emendas à Constituição e disse que "as pessoas estão preocupadas com as contas de eletricidade, não com a Constituição". Na Hungria, o processo de revisão constitucional foi orquestrado e dirigido pelos partidos políticos e pela imprensa. Estes corpos intermediários assumiram para si o poder extraordinário de substituir os cidadãos no processo de decisão mais importante, aquele de mudar as regras do jogo. A história da Hungria é a da ocupação do Estado por um partido majoritário com a ajuda de propaganda orquestrada que transforma minorias em bode expiatório das mazelas sociais e econômicas da nação. Essa foi uma velha história renovada.

\footnotetext{
${ }^{5}$ Jan-Werner Mueller, "Hungary's power-grab should make the EU rethink its role," The Guardian, 11 de março de 2013.
} 
Alguns meses antes, em 20 de outubro de 2012, os cidadãos da Islândia responderam positivamente ao referendo consultivo sobre a nova constituição, uma decisão que veio após um rico e aberto processo de debates envolvendo associações civis e cidadãos comuns por meio da internet ou encontros presenciais. $\mathrm{O}$ texto da constituição foi produto de um processo radicalmente democrático que não foi dirigido por uma maioria parlamentar. Em 2009, um ano após a crise financeira que explodiu e sacudiu a economia islandesa, organizações da sociedade civil tomaram a iniciativa de formar uma assembleia (composta por sorteio) para discutir e sugerir pontos de uma reforma constitucional. Em junho de 2010, o parlamento islandês, Althingi, aprovou a Lei 90/2010, estabelecendo uma Assembleia Constitucional consultiva, com a tarefa de revisar a constituição. O objetivo era envolver cidadãos na formulação de uma nova constituição, em parte com base em suas próprias informações e recursos (crowd-sourcing). Duas instituições foram estabelecidas: um Fórum Nacional de 950 cidadãos islandeses selecionados principalmente por sorteio e que concordavam que uma nova constituição era necessária, e um Conselho Constitucional de vinte e cinco membros foi eleito por sufrágio universal. Parlamentares e membros de partidos políticos não puderam concorrer como candidatos. O conselho aprovou uma nova carta depois de discuti-la diretamente com cidadãos pelo Facebook e Twitter.

A história da "revolução constitucional vinda de baixo" islandesa é um processo claramente único mas ao mesmo tempo conflitivo (que parece atualmente estagnado), levantando questões complexas sobre mudança e inovação constitucionais. Boa parte do impulso pela renovação política e constitucional veio da população islandesa, isto é, de cidadãos individualmente divergentes, intelectuais e organizações civis. ${ }^{6}$

Esta foi uma história completamente nova.

Essas duas histórias muito diferentes ocorreram na Europa, um continente desmantelado por uma crise econômica e financeira sem-fim, mas também um continente que é hoje local de profundas transformações políticas. Esses dois

\footnotetext{
${ }^{6}$ Baldvin Thor Bergsson and Paul Blokker, "The Constitutional Experiment in Iceland" (2013), acessado em 27 de fevereiro de 2014,

http://www.academia.edu/4505959/The_Constitutional_Experiment_in_Iceland.
} 
exemplos atestam, contudo, as vias esquizofrênicas que a democracia pode tomar ao se transformar no palco de um paradoxo gritante: enquanto sistemas políticos democráticos têm o apoio da opinião pública e emanam um encanto universal (as reformas húngaras foram promovidas em nome da defesa da democracia húngara), seus mecanismos existentes são pressionados e criticados, principalmente como resultado de um declínio na sua confiança. Ninguém ousa declarar-se não democrata ou antidemocrata, mas a tradução da democracia em um objeto de fé ideológica pode comprometê-la. Os cidadãos islandeses, como os húngaros, foram motivados por um desejo de revisar sua constituição por sua forte insatisfação com a forma pela qual suas instituições funcionavam, suas políticas operavam e as decisões eram tomadas. Eles atacaram suas democracias existentes com acusações (sustentadas por evidências) de corrupção, ineficiência, desperdício de recursos públicos, incompetência dos políticos e, sobretudo, que os corpos eleitos sistematicamente ignoravam a opinião dos cidadãos. Ideais de democracia não encaixavam perfeitamente na desconfiança das pessoas com a democracia na prática. Estes são sinais de um sério declínio na legitimidade de sistemas políticos democráticos - ainda que democracias desfrutem da preferência universal.

As trajetórias opostas trilhadas pela Hungria e pela Islândia também acertadamente indicam que o resultado das transformações políticas das quais as democracias são capazes é absolutamente incerto. Particularmente, os islandeses apontam para o fato de que nem a mídia tradicional ou os partidos tradicionais foram capazes de fazer com que cidadãos fossem ouvidos ou obrigar os políticos a ouvi-los. Mas o direito à liberdade de expressão e a nova mídia fizeram a distância entre as instituições e a sociedade parecer maior do que nunca. A revolta dos islandeses contra os partidos políticos pretendia reparar a democracia representativa recuperando o papel central dos cidadãos. Eles se voltaram, então, para os novos meios e tecnologias de informação e comunicação para apresentar suas reivindicações.

A democracia está passando por uma série de metamorfoses, mesmo quando as suas normas fundamentais não foram sujeitas a nenhuma mudança formal. Meu terceiro exemplo vem da Itália e trata-se da segunda história totalmente nova que gostaria de abordar. Nos anos 1990, Beppe Grillo, já conhecido por um público mais 
amplo como um comediante, abandonou a televisão nacional e reinventou sua carreira nos teatros e nas manifestações de rua como um crítico radical do tangentopoli (o nome do sistema nacional de corrupção política que promotores públicos trouxeram à tona em 1992). Isso revelou ao público mais amplo o quanto políticos haviam se tornado corruptos e corrompidos. Nos primeiros anos do século XXI, Grillo começou a liderar um movimento que reagia contra a proliferação de corrupção política com crítica satírica. Já em 2005 , ele havia se transformado de um orador de ocasião (soapbox speaker) em um verdadeiro agitador político. Isso se deu em considerável medida graças à criação de seu blog pessoal, beppegrillo.it, formulado e patrocinado pela empresa de Internet e editora de Gianroberto Casaleggio, uma operação na vanguarda da gestão de comunicações e de marketing digital. (Desde o início, o blog atraiu o interesse da imprensa internacional, que o classificou como um dos melhores na sua categoria, ganhando a admiração e apoio de Joseph Stiglitz). Assim, Grillo integrou dois tipos de fóruns, a piazza física e a piazza virtual, e transformou a participação via a expressão de opiniões na máquina de um novo movimento de contestação e participação.

Contudo, Grillo não estava satisfeito em liderar um movimento de protesto e opinião. Ele usou sua experiência de inovação tecnológica de uma maneira verdadeiramente original: para criar um ator político único e totalmente novo. Em poucos anos, o blog de Grillo se tornou uma arena de formação de opiniões, comunicação, propaganda e mobilização: ele divulgava informações e críticas sobre a política nacional e local, o capitalismo global e o consumismo, especulações relacionadas a patentes farmacêuticas e a exploração destrutiva do meio ambiente, dentre outras questões. Assim, Grillo abordou assuntos que eram tradicionalmente da alçada dos partidos verdes em um país que, diferentemente dos países europeus protestantes, nunca teve um partido ecologista que fosse capaz de influenciar a política nacional. De fato, o blog de Grillo era excepcional pela maneira em que casava a crítica política com a ecológica e transformava os temas ambientais em centrais para sua acusação de que a democracia praticada nas sociedades capitalistas, especialmente na Itália e na Europa, havia sofrido uma perda de legitimidade. ${ }^{7}$

\footnotetext{
${ }^{7}$ Piergiorgio Corbetta e Elisabetta Gualmini, org. Il partito di Grillo (Bologna: Il Mulino, 2013).
} 
Em suma, Grillo adicionou a ágora virtual à ágora física e criou uma amálgama de estilos diferentes de práticas políticas articuladas em torno da presença direta da opinião (usando formas de reunião "pesadas" [presenciais] e "leves" [via internet]), além de confiar tanto em blogueiros individuais quanto em movimentos de massa. $\mathrm{A}$ combinação do plebiscito e da internet é talvez a contribuição mais original feita por ele à política democrática. Não foi, contudo, a única. Grillo buscava algo mais ambicioso: tornar o seu blog um ator político no sentido mais pleno. Assim, fez o blog agir com uma mistura de funções novas e velhas: atraindo seguidores e criando uma identidade forte, mas também criando uma expertise em captar e difundir notícias ou estabelecendo encontros de grupos que iriam levantar questões, lançar plataformas de discussão e preparar para propaganda e mobilização. Em poucos meses, o blog se tornou um movimento político. Sem mudar a sua identidade não-partidária (ou mesmo anti-partidária), beppegrillo.it deu à luz um partido eleitoral sem se tornar um. Com o nome de "Movimento 5 Estrelas" ou "M5S" (Movimento 5 Stelle), o grupo de Grillo teve um bom resultado nas eleições administrativas e ganhou o controle do conselho municipal e do cargo de prefeito de Parma, uma das cidades industriais mais ricas do norte da Itália. Depois, ele chegou ao parlamento com o equivalente a vinte e cinco porcento dos votos nas eleições de 24 e 25 de fevereiro de 2013.

Apesar de não formalmente reescrever a constituição, o M5S influenciou a revisão da prática política como algo organizado e dirigido pelos partidos políticos. Ou seja, o M5S introduziu um elemento "direto" na democracia representativa, fazendo surgir o que eu descrevo com um oxímoro: democracia representativa direta, na qual o elemento "direto" é visual e comunicativo e cria uma democracia representativa de transmissão ao vivo ao invés de participação direta, de acordo com a demanda e o sentido clássicos de autonomia política. A internet torna centrais a influência ou conversas visuais e interativas de cidadãos comuns, mas não o seu poder de autorização na tomada de decisão. Assim, enquanto alguns acadêmicos propõem categorizar este tipo de movimento como populista, outros defendem que, apesar de compartilhar algumas das suas preocupações com o populismo de direita (por exemplo, sua posição anti-imigração e antieuropeia), ${ }^{8}$ ele lida com um novo tipo de

\footnotetext{
${ }^{8}$ Pierre-André Taguieff, Le nouveau national-populisme (Paris: CNRS, 2012).
} 
sujeito político, que se caracteriza não pelo apelo ao povo como uma entidade unificada, mas sim pela comunicação horizontal entre cidadãos. ${ }^{9}$ Se a televisão foi central para a formação de um movimento plebiscitário em torno da figura de Silvio Berlusconi ou da videocracia, foi a internet que facilitou as formas diretas de presença democrática de beppegrillo.it por meio do julgamento e da opinião.

Este terceiro caso de mutação na prática da democracia representativa acompanha o caso islandês na sua experimentação radical, e o caso húngaro na sua contestação ao parlamentarismo a favor de decisões que refletem a opinião da maioria de maneira mais direta e sem (ou até mesmo contra) a cacofonia de partidos políticos. Estas transformações, ainda que diferentes, coincidiram com (e são efeito colateral de) uma série de crises econômicas e políticas que pressionaram as autoridades democráticas a fortalecer o papel do executivo (tanto no nível nacional como no europeu) para lidar com a autoridade do mercado, particularmente com o investimento financeiro e as agências de notação de risco de crédito. O resultado não é somente uma crise econômica e social, mas também uma crise que diz respeito à credibilidade e à eficiência dos procedimentos e instituições de tomada de decisão, em especial o parlamento.

\section{A virada anti-partido}

Programas e estilos fortemente anti-partido caracterizam as duas histórias completamente novas que esbocei. Junto com a multiplicação de opiniões que a liberdade de imprensa e de expressão fomentou, os partidos políticos foram por décadas as instituições que fizeram da democracia representativa uma ordem política complexa de poderes indiretos e mediados baseados no consentimento eleitoral e na participação. É impossível entender a representação sem entender o significado, o papel e a função do partido político. Na era do governo representativo, os partidos têm quatro feitos centrais:

\footnotetext{
${ }^{9}$ Roberto Biorcio e Paolo Natale, Politica a 5 stelle: Idee, storia e strategie del movimento di Grillo (Milan: Feltrinelli, 2013).
} 
1. Conectar a sociedade civil e o Estado ou fazer com que seja possível para instituições contar com opiniões e interesses que unem ou dividem cidadãos sem que sejam sua expressão direta (o que torna um partido diferente de uma facção). Partidos políticos fazem com que cidadãos, que em outras esferas podem divergir em muitos aspectos, convirjam em direção a um programa geral ou a uma narrativa que os unifica na medida em que os opõe a outros programas ou narrativas, criando assim as condições para a competição política aberta em busca de representação e, finalmente, da maioria.

2. Exercer um mandato político (que é necessário uma vez que o mandato imperativo está excluído) por meio do controle dos eleitos e induzir as suas decisões parlamentares para que sejam, tanto quanto possível, consistentes com o programa do partido.

3. Circular opiniões entre o lado de dentro e o lado de fora das instituições para manter o espaço aberto à participação e fazer dos cidadãos mais do que simples eleitores, mas também participantes na formulação de programas políticos e, finalmente, controladores.

4. Tornar possível a formação de uma classe política de administradores e políticos por meio de um processo de formação e treinamento que é, em teoria, aberto a todos cidadãos que querem entrar na política.

Em países europeus, e na Itália mais especificamente, a crise que os partidos políticos vivenciaram nos anos recentes se refere a algumas ou mesmo todas estas características, uma vez que os partidos se tornaram mais radicais ou polarizados, e são, portanto, menos capazes de alcançar compromissos ou atrair opiniões e interesses mais amplos e menos sectários. Além disso, eles se tornaram profundamente personalistas e hoje em dia mal são capazes de exercer a autoridade sobres seus membros eleitos. Soma-se a isso o fato deles terem diminuído sua função como veículos de participação e se tornado cada vez mais isolados no parlamento e nas instituições políticas. Finalmente eles não são mais os únicos na função de formar 
e treinar a classe política (empresas privadas, universidades e bancos também cumprem esta função). ${ }^{10}$

O crescimento do movimento de Grillo, assim como o processo de reforma constitucional da Islândia, acompanhou o declínio do partido político como uma forma de participação e da política representativa que o partido havia tornado possível. ${ }^{11}$ Enquanto o M5S usou a seleção e a discussão pela internet para construir a sua lista de candidatos ao parlamento, os islandeses usaram o sorteio como uma estratégia de seleção alternativa às eleições para determinar os membros da assembleia que iriam discutir as propostas de reforma constitucional (apesar de terem usado eleições para selecionar o conselho constitucional propriamente dito). A seleção por sorteio tem sido associada à democracia desde a antiguidade, porque, diferentemente das eleições, ela é verdadeiramente igualitária: ela não divide o corpo dos cidadãos (entre os poucos de decidem sobre leis e os muitos que votam por eles), e seu princípio é o de que todos os cidadãos deveriam ter a chance de governar e de serem governados. Depois das repúblicas humanistas italianas (que o utilizaram intensamente), o sorteio desapareceu da política, apesar de ainda estar presente na prática jurídica, abrindo o caminho para a forma de seleção eleitoral. Hoje, em conjunto com a crise dos partidos políticos e o uso massivo da internet, o sorteio aparece como útil uma vez mais. ${ }^{12}$

Junto com o sorteio, é necessário mencionar outras novas formas de consulta praticadas nas democracias contemporâneas (e foram usadas no processo de revisão constitucional na Islândia), como assembleias deliberativas de cidadãos, orçamento participativo e várias formas de júri de consulta popular, nas quais formas tão diversas como democracia deliberativa, eleições e sorteio funcionam juntas. Esses fóruns ou encontros de cidadãos organizados ou selecionados e especialistas designados em comitês ad hoc para a resolução de problemas ou para a avaliação crítica de temas controversos são o novo terreno no qual o poder de controle do cidadão-juiz mostra

\footnotetext{
${ }^{10}$ Mauro Calise, Il partito personale. I due corpi del leader (Rome-Bari: Laterza, 2000); Piero Ignazi, Sul partito politico (Rome-Bari: Laterza, 2012).

${ }^{11}$ Carl J. Friedrich, Man and his Government: An Empirical Theory of Politics (New York: McGraw, 1963), 509-23. As organizações de partidos politicos fortalecem accountability no decorrer do tempo porque elas "encorajam representantes atuais a dar mais atenção a 'eleitores' futuros"; Dennis F. Thompson, "Democracy in Time: Popular Sovereignty and Temporal Representation," Constellations 12 (2005): 258. 12 Yves Sintomer, Histoire de L'expérimentation démocratique: tirage au sort et politique d'Athènes à nos jours (Paris: La Découverte and Poche, 2011).
} 
seus efeitos irrefutáveis contra as decisões tomadas no nível institucional. Também nesse caso, o sistema eleitoral e os partidos políticos são suplantados e desafiados. ${ }^{13}$

A percepção das pessoas sobre o significado da cidadania, como algo que é identificado com o bem geral, está pronta para mudanças acompanhando a crescente complexidade dos processos de tomada de decisão. As atitudes de um público de cidadãos são hoje representativas da transformação nas nossas sociedades democráticas. Como Bernard Manin observou, a democracia do público substituiu a democracia de partido, fazendo com que a cidadania não seja mais tão associada com a participação na formulação ou na seleção de uma agenda ou de candidatos para um governo futuro, mas com o comparecimento visual de uma audiência indistinta de espectadores. ${ }^{14} \mathrm{~A}$ dimensão presente da performance é mais importante que a perspectiva futura que a democracia de partidos trazia para as eleições. O M5S confirma a validade deste diagnóstico.

O blog de Grillo alimenta a ambição de selecionar candidatos como competidores individuais, sem a afiliação a um grupo político. Sua experiência inicial desde as últimas eleições nacionais demonstrou, contudo, que este não pode ser entendido como um ideal de representação democrática, uma vez que pode efetivamente se afastar dos princípios do governo representativo. ${ }^{15}$ De fato, se as eleições fossem verdadeiramente uma seleção entre e de candidatos individuais - de e entre pessoas com bons currículos, em vez de membros de grupos políticos com programas e ideias específicas - a representação desapareceria porque cada candidato, se eleito, se tornaria partidário das suas próprias visões e interesses. ${ }^{16} \mathrm{O}$ arranjo legislativo seria uma agregação de vontades individuais mais ou menos como a

\footnotetext{
${ }^{13}$ Sobre as várias formas de experimentação em cidadania deliberativa, começando com o orçamento participativo de Porto Alegre, ver Rebecca Neaera Abers, Inventing Local Democracy: Grassroots Politics in Brazil (Boulder, CO: Lynne Rienner, 2000); John S. Dryzek, Deliberative Democracy and Beyond: Liberals, Critics, Contestations (Oxford: Oxford University Press, 2000); Archon Fung e Eric Olin Wright, Deepening Democracy: Institutional Innovations in Empowered Participatory Governance (London: Verso, 2003).

${ }^{14}$ Bernard Manin, The Principles of Representative Government (Cambridge: Cambridge University Press, 1997), 221-33.

${ }^{15}$ Manin, The Principles of Representative Government, 220.

16 "Nós não apenas escolhemos um presidente ou decidimos sobre uma lei [quando votamos]. Nós escolhemos todo um mundo no qual tudo está estabelecido", Russell Hardin, "Public Choice Versus Democracy," in The Idea of Democracy, org. David Copp, Jean Hampton, e John E. Roemer (Cambridge: Cambridge University Press, 1993), 161.
} 
assembleia em uma democracia direta, embora sem ser igualmente inclusiva e direta. Para ser uma seleção de cidadãos individuais sem afiliação partidária, as eleições necessariamente precisam ser associadas com um mandato imperativo. Mas a representação sem o mandato imperativo precisa ser mais do que a nomeação de notáveis via eleições; eleições que ocorram em um contexto político que envolva programas relacionados ao governo futuro pressupõem alguma organização (portanto partidos políticos) que seja capaz de atrair e unificar as ideias e os interesses dos cidadãos (ou seja, seus votos). Votar pelo Sr. Smith sempre implica também votar pelo que o Sr. Smith diz e acredita e, inevitavelmente, pelo que nós acreditamos e defendemos por meio do Sr. Smith. ${ }^{17}$

O movimento anti-partido M5S, na realidade, não libera o parlamento dos partidos políticos. ${ }^{18}$ Ele mostrou que seus representantes são, na realidade, mais sujeitos ao poder dominante do líder do movimento que os representantes eleitos nos partidos tradicionais. Um partido não-organizado é, afinal, um partido que depende inteiramente da vontade de seu líder, e por isso é menos democrático que uma associação política governada por órgãos eleitos de acordo com procedimentos que são regulados por normas escritas em uma carta de compromisso. O movimento de Grillo é uma organização privada que reproduz os vícios da liderança de Berlusconi de maneira talvez até mais radical. O líder cria o movimento e reivindica para si a posição de único porta-voz representativo. Contudo, isso cria problemas adicionais: a ambição de Grillo é a de impor aos representantes do M5S o que eles devem dizer e como eles devem votar no parlamento, sem lhes permitir liberdade de pensamento e decisão. Enquanto a constituição italiana proíbe o mandato imperativo, Grillo recuperou o poder de vincular e controlar os representantes do M5S. A promessa do seu movimento de tornar a política horizontal se transformou na atualização de uma nova forma de dominação, com o paradoxo de que os representantes do M5S estão livres da vontade impositora do líder do movimento precisamente porque eles não estão sujeitos a nenhum mandato imperativo. Em suma, sua responsabilidade como

\footnotetext{
${ }^{17}$ Norberto Bobbio, “Il compito dei partiti politici," em Tra due repubbliche: Alle origini della democrazia italiana, org. Tommaso Greco (Rome: Donzelli, 1996), 119-24.

${ }^{18}$ Dario Fo, Gianroberto Casaleggio e Beppe Grillo, Il grillo canta sempre al tramonto: dialogo sull'Italia e il Movimento 5 Stelle (Milan: Chiarelettere, 2013), 79-99.
} 
representantes do seu movimento se apoia na organização da democracia parlamentar, cuja performance requer e pressupõe partidos políticos.

\section{Jornalismo autoproduzido}

Os seguidores de Grillo e os islandeses, que tentaram re-escrever sua constituição sem e contra os partidos políticos, consideram a imprensa tradicional e os canais de televisão não menos culpados de inépcia e manipulação do consentimento que os próprios partidos políticos. Por outro lado, a internet possibilita a existência de formadores de opinião não profissionais e acesso barato às opiniões, duas condições que permitem que cidadãos dispensem o jornalismo profissional. O M5S e os islandeses têm um ponto aqui, porque é certo que o aparecimento de novas mídias (a internet e as redes sociais) constitui uma transformação tão importante quanto foi a alfabetização em massa, o desenvolvimento da indústria da publicidade ou a invenção da televisão. A multiplicação de vias de comunicação, já em movimento com a liberalização dos meios tradicionais e o desenvolvimento da televisão à cabo e via satélite, também levou à democratização do acesso à informação. Estes são fatos subjacentes ao ataque cotidiano de Grillo contra a indústria da informação, em nome do jornalismo horizontal como a nova fronteira de democratização.

Beppegrillo.it alega ser, portanto, a fonte de informação mais confiável, e seus blogueiros são cidadãos que, como Sherlocks Holmeses autofabricados (self-made), coletam dados, fazem perguntas e divulgam notícias: fontes oficiais de informação são dispensadas e tachadas de pouco confiáveis, enquanto jornalistas profissionais aparecem como remanescentes de um sistema de monopólio antigo de formação de opinião. O impacto da desprofissionalização do jornalismo ainda é difícil de avaliar e vai além da experiência do movimento de Grillo.

Uso aqui o termo democratização em um sentido descritivo e para caracterizar dois fenômenos que são consistentes com igualdade e liberdade. A internet estende o papel de atores não-profissionais na coleta e na circulação de informação e desta forma pode ser vista como uma expansão da igualdade política para além do domínio do voto, na esfera da formação de opinião. Como o arauto na descrição da polis de 
Aristóteles, os cidadãos tornam-se os fornecedores da informação necessária para fazer julgamentos políticos sem que nenhuma agência intermediária escolha o que publicar e apresente sua interpretação. Na democracia contemporânea, em vez disso, televisão e jornais se tornaram grandes negócios, em número muito pequeno para servir uma grande população letrada, o que tem como consequência o fato destes meios não serem apenas veículos que transportam ideias e opiniões, mas poderes colocados em poucas mãos que informam e moldam a opinião pública. A questão aqui não é simplesmente que nem todos têm acesso igual ao mercado das ideias, mas também que alguns têm uma voz mais alta que outros graças à riqueza material que eles detêm e utilizam para amplificar sua voz e defender suas agendas com maior facilidade. Os meios tecnológicos da informação - tanto os tipos tradicionais, como os materiais impressos, quanto os novos - requerem dinheiro, e o dinheiro fatalmente traz interesses privados e disparidades econômicas para dentro da política. A igualdade foi violada de maneira substancial, e isto é um desafio à liberdade política. ${ }^{19}$

Além disso, a internet tem o poder de tornar autoridades públicas mais expostas à inspeção e menos capazes de agir em segredo. A internet pode remover o que talvez seja o obstáculo mais resiliente para o aprofundamento da democracia no nível estatal. Nesse sentido, ela registra uma expansão da liberdade política, já que subverte os privilégios de conhecimento dos funcionários governamentais. Dois casos recentes conhecidos ilustram essa tendência. É simplesmente extraordinário que o Presidente Barack Obama e sua equipe na Casa Branca confiaram em um filme que foi transmitido por um micro-blogueiro em Abbottabad para assistir a invasão das forças especiais norte-americanas à residência de Osama Bin Laden. Igualmente extraordinários são os vazamentos explosivos de Edward Snowden sobre a extração e compilação de dados eletrônicos pela Agência de Segurança Nacional estadunidense e sobre a prática dos Estados Unidos de vigilância sistemática das comunicações privadas e governamentais de milhões de indivíduos em vários países (mesmo aliados), e a divulgação de

19 Chris Demaske, Modern Power and Free Speech: Contemporary Culture and Issues of Equality (Lanham, MD: Rowman \& Littlefield, 2009), 39-41. O argumento que a liberdade de opinião tem uma relação direta com o princípio de auto-determinação foi feito por Justice Louis Brandeis em 1920, e foi revisado recentemente por Robert C. Post, "Recuperating First Amendment Doctrine," Stanford Law Review 47 (1995): 1249-81. 
memorandos diplomáticos e relatórios confidenciais produzidos por diversos governos ao público global pelo WikiLeaks.

Teria a imprensa profissional (accredited) se tornado supérflua como meio de deliberação pública, uma vez que a internet tem possibilitado o acesso à informação de forma mais equitativa e dá aos cidadãos comuns a oportunidade de desempenhar um papel direto na obtenção e avaliação de informações relevantes? As esperanças trazidas pela multiplicação de vias de comunicação são compreensíveis apenas nos termos da crítica aos meios de comunicação tradicionais. Em contraposição aos meios que mantêm uma correspondência entre aqueles que são ao mesmo tempo receptores e emissores, os meios de comunicação de massa tradicionais não permitem ao leitor, ao ouvinte ou ao espectador responder imediatamente ao que foi dito pelo mesmo canal. Comunicação interativa e a absorção de informações coletadas por agências públicas e privadas que os cidadãos não controlam são as diferenças importantes na teoria e na prática atuais da deliberação pública. Esta transformação está mudando o significado da liberdade de expressão.

A visão liberal clássica do papel da imprensa - incorporada na proteção constitucional da liberdade de expressão, nos códigos de ética jornalística, e nas críticas às limitações da mídia - está a ponto de enfrentar uma mudança radical na medida em que a forma de comunicação pública muda. O hiato entre o ideal de uma imprensa que garante a integridade do debate público e as formas tecnológicas, culturais e econômicas de comunicação de massas tem sido criticado desde o século XIX (J. S. Mill e Tocqueville foram seus críticos pioneiros). John Dunn perguntou recentemente como é possível que o fórum público de ideias tenha êxito em permanecer um bem público e em desempenhar seu papel cognitivo, discordante e vigilante, se a indústria da informação, que afeta a política de maneira tão radical em tantas partes diferentes do mundo, pertence a um número relativamente pequeno de indivíduos privados. ${ }^{20}$ Sob a pressão de restrições cada vez mais fortes na seleção, os jornais independentes do lluminismo europeu que haviam assegurado a existência de

\footnotetext{
20 John Dunn, Democracy: A History (New York: Atlantic Monthly Press, 2005), 175. O mesmo pode ser dito de redes de comunicação de maneira mais geral, que são "em sua maioria detidas e geridas por redes de corporações midiáticas globais" e, apesar de Estados serem parte destas redes, "o coração da rede de comunicação global é e amplamente dependente de investidores e mercados financeiros." Manuel Castells, Communication Power (Oxford: Oxford University Press, 2009), 424.
} 
uma esfera pública de discussão em contextos formais e informais cederam lugar a uma indústria de relações públicas que se rendeu à influência dos meios de comunicação de massas que estão a serviço dos interesses privados (as recentes operações eletrônicas clandestinas da Agência Nacional de Segurança dos Estados Unidos revelam a interligação dos interesses governamentais e corporativos no compartilhamento de informações que podem influenciar os assuntos políticos e econômicos globais). Um século depois de Mill e Tocqueville, Jürgen Habermas defendeu que o fórum público é essencial à democracia desde que se mantenha público, pluralista e autônomo em relação aos interesses privados de diversos tipos. Profético, em 1962, Habermas retratou o estilo de aclamação que pode desfigurar a esfera pública na democracia de massa. ${ }^{21}$ Agora, a última revolução da mídia marcou uma ruptura no processo de comunicação pública, derrubando a concepção clássica sobre o papel democrático da imprensa, questionando o impacto negativo da prática jornalística tradicional e a propriedade privada dos meios de comunicação sobre a deliberação democrática. É nesse sentido que a democracia do público (para adotar uma expressão de Bernard Manin) se tornou uma categoria útil para detectar o significado e a implicação de uma nova forma de democracia de audiência, ou uma democracia representativa de transmissão ao vivo.

\section{A transparência e a soberania da audiência}

Ao concluir esta breve revisão de algumas mutações na prática da democracia, gostaria de levantar três conjuntos de questões programáticas. O primeiro pertence à visão totalizada do público, que parece absorver toda a atividade política - ver e julgar se tornam funções mais importantes que votar e decidir. As mudanças na prática política que analisamos contribuíram para a redefinição da tarefa do cidadão como essencialmente visual; cidadãos são o público, um agente ocular indistinto que como o panóptico de Bentham inspeciona o que os líderes fazem. Contudo, a cidadania não se resume ao julgamento e à demanda por transparência, mas também envolve uma

\footnotetext{
${ }^{21}$ Jürgen Habermas, The Structural Transformation of the Public Sphere: An Inquiry into a Category of Bourgeois Society, trad. Thomas Burger, com o apoio de Frederick Lawrence (Cambridge, MA: MIT Press, 1991), particularmente 211-22.
} 
participação ativa no processo de tomada de decisão regulado por procedimentos com o objetivo de produzir leis. Mas os cidadãos de uma democracia de audiência querem participar no espetáculo da política como uma audiência em um teatro, onde os papéis são interpretados segundo um roteiro que não conta com a contribuição da audiência, e cuja participação consiste majoritariamente em uma reação às notícias e aos rumores que a internet e a mídia circulam e pelos quais ninguém é responsável.

A segunda questão pertence à transparência. A demanda por transparência é sintomática da ambiguidade contida no mito da transparência. De fato, a busca da mídia por transparência está longe de ser simples, porque ela é gerida por especialistas de comunicação e informação que publicam somente as notícias ou imagens que melhor atraem o público e provocam emoções reativas, como inveja, admiração, repulsa, e assim por diante. Produzir efeitos emocionais é a função da mídia e da internet, que tendem então a reproduzir não-transparência no exato momento em que afirmam produzir transparência e conhecimento total. ${ }^{22}$ Como os cidadãos italianos aprenderam, a videocracia de Berlusconi produziu o paradoxo de fazer a vida do seu líder permanentemente visível ao público como um espetáculo, mas esta mesma transparência total teve como efeito ocultar exatamente aquilo que os cidadãos necessitavam saber, notadamente os atos e as transgressões dos políticos. ${ }^{23}$ A visibilidade total do poder teve como efeito calculado a geração de opacidade. Mas segundo Grillo, a transparência demonstra seus efeitos benéficos uma vez que os corpos intermediários - a mídia profissional e os partidos políticos - são finalmente substituídos por movimentos horizontais.

O mito da transparência requer uma análise crítica própria. Não há dúvidas de que ele está prestes a mudar o tom das relações políticas, já que pode ser um obstáculo formidável à mediação e ao estabelecimento de compromissos entre os partidos políticos sobre os quais se assenta o processo democrático de tomada de decisão. Os blogueiros de Grillo e os representantes do M5S são profundamente hostis

\footnotetext{
${ }^{22}$ Como Niklas Luhmann argumentou de maneira convincente, a opacidade é implícita no paradigma do espectador total porque "oferecido de fora, o entretenimento tem como objetivo ativar aquilo que nós próprios experimentamos, anseios, medos, esquecimento - assim como a narração de um mito fez no passado." Niklas Luhmann, The Reality of the Mass Media, trad. Kathleen Cross (Stanford, CA: Stanford University Press, 2000), 58.

${ }^{23}$ Giovanni Sartori, Comparative Constitutional Engineering: An Inquiry into Structures, Incentives and Outcomes, 2nd ed. (New York: New York University Press, 1997), 148.
} 
à mediação e ao compromisso (duas práticas que associam à hipocrisia, insinceridade e o comportamento ambíguo dos partidos políticos) e advogam pela transmissão direta on-line de tudo que acontece no âmbito institucional. Mas a prática de transmissão direta pela internet do encontro dos representantes do M5S com os representantes do Partido Democrático com o objetivo de formar um novo governo (depois das últimas eleições de fevereiro de 2013) foi um grande obstáculo à tomada de decisão. A transparência impediu qualquer acordo possível e paralisou a tomada de decisão. De fato, logo se tornou claro que os representantes do M5S usaram publicidade e transparência mais para fortalecer a lealdade dos seus membros do que para facilitar a sua participação visual no processo de tomada de decisão.

Finalmente, a última questão pertence à própria democracia na internet, um fenômeno extremamente novo cujo impacto na democracia ainda é impossível de prever. A internet vai mudar radicalmente a figura do cidadão, ou seja, a identidade política à qual o sufrágio atribui o papel de responsabilidade individual e que expressa sua vontade por meio do voto pessoal (protegido pelo sigilo, não pela transparência). A internet cria a circulação de opiniões cujos precursores individuais são quase impossíveis de identificar, enquanto ela tende a agregar cidadãos de acordo com sua lealdade a determinados temas ou crenças. ${ }^{24} \mathrm{~A}$ democracia na internet despersonaliza a interação entre as pessoas precisamente quando torna o domínio privado (a comunicação individual segundo um julgamento subjetivo) o único domínio da política. O paradoxo da formação de opinião como um poder que absorve a cidadania na sua totalidade é o seguinte: por um lado, a prática de transmissão on-line ou de participação visual via internet torna os cidadãos confiantes na sua retomada de poder sobre representantes eleitos, mas por outro lado, ver coisas que acontecem ou comentar sobre elas não envolve ter controle das intenções e dos objetivos que guiam os agentes.

\footnotetext{
${ }^{24} \mathrm{~A}$ internet distribui uma quantidade considerável de informação e despersonalização, mas ela tende a agregar milhões em torno de perspectivas que, como Cass Sunstein observa, são endossadas pela imitação e tendem a reproduzir e radicalizar lealdades preconceituosas velhas e facciosas. Cass Sunstein, Infotopia: How Many Minds Produce Knowledge (Oxford: Oxford University Press, 2006), 5-19.
} 


\section{Mutações, incertezas e a abertura ao possível}

Como seria a democracia representativa com participação via internet e sem partidos políticos, ou segundo o modelo proposto pelo M5S e aplicado de forma ainda mais radical na Islândia? Mais especificamente, uma vez que a identificação da democracia com procedimentos de tomada de decisão foi contestada em nome da promoção de uma participação mais sincera e não-mediada, como podemos ter certeza de que a maioria ainda é o princípio da democracia se a opinião consiste na contribuição da minoria mais ativa ou daqueles cidadãos que participam de maneira mais persistente e efetiva na internet ou nas ruas? Como podemos assegurar que o povo soberano, que a democracia representativa era capaz de incorporar por meio de procedimentos e regras bem desenhadas, não é meramente identificado com a multidão ou com uma massa indeterminada de usuários mais ativos ou profissionais da internet? Substantivamente, como podemos proteger a igualdade política e o princípio da maioria no contexto de um movimento de opinião que recompensa aqueles com a voz mais alta ou que passam mais tempo na rede? Estas questões dão uma ideia das implicações enormes do que eu tenho chamado de democracia representativa de transmissão ao vivo.

Comecei este artigo com o paradoxo de que a hegemonia do ideal de democracia é combinada com a insatisfação prática com as suas instituições. Este paradoxo motiva curiosidade crítica e uma inspeção imparcial destes novos processos. Ele é consistente com a natureza diárquica da democracia, que é tanto um sistema político (que promulga leis e demanda obediência) quanto uma forma de ação política por cidadãos livres e iguais - ou seja, ela é tanto "vontade" (decisões de autoridade feitas segundo procedimentos consentidos) e "opinião" (a dimensão complexa e plural da formação e manifestação da opinião em sociedade). A democracia consiste no reajuste permanente do equilíbrio entre o poder das normas e procedimentos de um lado e aquele das opiniões de outro. Esta identidade dual está na fonte da força inovadora extraordinária da democracia, uma energia que é capaz de subverter o poder estabelecido, questionar o fatalismo do status quo e, sobretudo, a rejeição prejudicial de novas formas de atividade e normas. Hannah Arendt definiu a política como 
natalidade, dar à luz a novas formas de poder por meio de processos de interação no público entre cidadãos livres e iguais que escolheram confiar somente em palavras e persuasão. ${ }^{25}$ Hoje estamos testemunhando uma nova onda de política criativa e de remodelação dos processos políticos, ainda que talvez menos atraente que a experiência revolucionária que inspirou Arendt. Mas as inovações democráticas aconteceram no atoleiro da prosa, da vida cotidiana cheia de contradições, dos eventos e implicações que podem até ser desagradáveis: e enquanto o jogo estiver em andamento, pode ir em qualquer de muitas direções, cada qual possivelmente oposta às demais. As mutações que estamos testemunhando falam da natalidade no ordinário, e o caso da Islândia é particularmente interessante nesse sentido, sendo certamente o mais radical em sua realização e o mais promissor em seu resultado.

A incerteza do resultado da Islândia demonstra a abertura e as implicações arriscadas da experimentação democrática. Antes que ocorresse o referendo consultivo de outubro de 2012, foi lançado um relatório de três acadêmicos constitucionalistas que tinham a tarefa de avaliar o esboço da constituição. Estes juristas consideraram o esboço como o resultado de um processo tremendamente inovador e participativo, e a constituição como a mais inclusiva da história, certamente mais inclusiva do que os processos constituintes tradicionais que ocorreram após a Segunda Guerra Mundial. Depois que o referendo ocorreu, uma revisão internacional ainda mais ampla foi empreendida pela Comissão de Veneza ou Comissão Europeia para a Democracia pelo Direito. A opinião publicada pela comissão em março de 2013 confirmou o entendimento dos especialistas: enfatizou a importância da natureza participativa do processo de elaboração constitucional, assim como a relevância do envolvimento direto dos cidadãos na formulação da lei fundamental. A comissão não economizou críticas ao documento e apontou que um número relativamente alto de disposições foram formuladas de maneira muito vagas ou amplas e que as propostas de tomadas de decisão e de mecanismos participativos pareciam muito complicados. ${ }^{26}$ De todo modo, a Comissão Europeia esteve aberta às possibilidades - com uma atitude atenta e não censória às mutações da democracia. Cidadãos comuns em ação

\footnotetext{
${ }^{25}$ Hannah Arendt, The Human Condition (Chicago, IL: University of Chicago Press, 1959), 7-9.

${ }^{26}$ Bergsson and Blokker "The Constitutional Experiment in Iceland," 31.
} 
foram criticados pela sua experiência limitada no trabalho legislativo, mas também houve o reconhecimento de que foram capazes de produzir um documento constitucional persuasivo. Na realidade, os islandeses não queriam substituir suas instituições, e o seu trabalho supunha que o projeto de Constituição deveria ser levado ao Althingi para ser concluído. Contudo, assim que o documento chegou ao parlamento, o processo parou. Os partidos da coalizão resultantes das últimas eleições não tiveram êxito em chegar a qualquer posição sobre a carta, e, como resultado, os islandeses ainda estão, no momento em que escrevo, esperando a aprovação de sua constituição.

O caso da Islândia evidencia as implicações possíveis da identidade dual da democracia e como a ruptura do equilíbrio entre dois domínios - o institucional e o extrainstitucional - pode estar na fonte de tensões entre as forças transformadoras e conservadoras da ordem democrática. Além disso, os casos da Islândia e da Hungria demonstram que a posição tomada pelo establishment deveria ser objeto de preocupação maior do que as inovações que cidadãos tentam pôr em ação na sua tentativa de recuperar sua autoridade sobre o processo político. Finalmente, o caso do movimento de Grillo demonstra quão radical pode ser o impacto da revolução dos meios de comunicação no funcionamento da democracia representativa. Quando Grillo critica o jornalismo profissional e os especialistas das corporações midiáticas pela sua servilidade aos interesses corporativos privados e aos executivos estatais, ele põe o dedo na questão da legitimidade. Ao retirar confiança da indústria da informação, ele afirma que blogueiros são uma fonte de informação mais confiável e legítima e, além disso, que a cidadania envolve não somente a autonomia política, mas também autonomia no trabalho de produção de opiniões nas quais seu julgamento se baseia.

Em todos os três casos, vemos a diarquia da democracia em ação, sua identidade dual, que pode constituir uma fonte de inovação que em si mesma não é livre de efeitos inquietantes. Portanto, a abertura ao possível seria a atitude que nos permite apreciar as mutações correntes sem prescindir de adotar uma atitude crítica frente às suas implicações. Na realidade, não há alternativa a essa atitude, uma vez que a democracia é uma forma de vida política entre adultos que navegam 
permanentemente no domínio na incerteza, a partir do momento em que eles renunciam submeter suas decisões a autoridades que não podem ser responsabilizadas, sejam elas dinheiro ou divindade, habilidade competente ou a sabedoria de poucos. 